\title{
Permaculture as a foundation for sustainable interaction design and UX
}

\author{
Callum Egan \\ Edinburgh Napier University \\ 10 Colinton Road, \\ Edinburgh, EH10 5DT \\ callum.egan@napier.ac.uk
}

\author{
David Benyon \\ Edinburgh Napier University \\ 10 Colinton Road, \\ Edinburgh, EH10 5DT \\ d.benyon@napier.ac.uk
}

\author{
Richard Thompson \\ Edinburgh Napier University \\ 10 Colinton Road \\ Edinburgh, EH10 5DT \\ rthompson1987@hotmail.co.uk
}

\begin{abstract}
The main objective of this work is to gain an understanding of the relationships between UX and permaculture. This will deliver insights as to how digital media development can support the need for people to live and work in more ecologically conscious ways and how UX design can become more sustainable. In this respect, it is an attempt to produce sustainability both in and through design.
\end{abstract}

\begin{abstract}
We employ a makers approach to understanding permaculture and its relationships with UX in both physical and digital spaces. The work utilizes ideas from blending theory (Fauconnier and Turner, 2002) to generate conceptualizations of ecologically effective sustainable interaction design (SID) spaces. We employ material anchors to ground complex ideas of sustainability in augmented physical gardens.
\end{abstract}

Permaculture. Blended Spaces. Sustainable Interaction Design. User Experience. Gardens.

\section{INTRODUCTION}

Within and beyond the user experience (UX) design community there is a long-standing turn toward exploring how to think, live and work 'sustainably'. The current era has been dubbed the 'Anthropocene' (Latour, 2014; Zalasiewlcz, et al., 2010) indicating humankind's agency in climate change. We face a future that may involve significant reduction in the supply and consumption of traditional forms of energy (Tomlinson, et al., 2013). The ethos of sustainability is evident in the use of rare materials and the principle of re-use in design. In non-material forms across design we also see sustainability invoked in relation to people, where it has come to describe forms of community-design and local cultures of production.

Braungart and McDonough's (2008) groundbreaking work 'Cradle to Cradle' provides a helpful broad viewpoint on this narrative. They posit a remaking of processes, systems, products and designs so that productive inputs and outputs nurture either biological or technological systems. They explain:

\footnotetext{
"Eco-effective designers consider the whole. What are the goals and potential effects, both immediate and wide-ranging, with respect to both time and place? What is the entire system cultural, commercial, ecological - of which this
}

made thing and way of making things will be a part."

This work is sympathetic to a radical, imaginative design for sustainability discourse (Dryzek, 2005) and furthers the holistic focus of Knowles et al's contribution to the sustainable interaction design (SID) literature of a "quadruple bottom line". This binds economic concerns to social, environmental and personal needs, framing sustainability as a problem of how to enable human fulfilment (Knowles, et al., 2013). Furthermore, by invoking 'sustainability' in the context of interaction design (and human-computer interaction, $\mathrm{HCl}$ ) and $\mathrm{UX}$ we necessarily charge UX designers with ethical responsibilities at a human and non-human level.

We use the term user experience (UX) to describe what happens when people use technologies. User Experience (UX) is about engagement and interaction (Benyon, 2017). It is an emotional as well as cognitive response to some technologies and content. Sometimes UX focuses on achieving a goal (Hassenzahl and Tratinsky, 2006), but often UX is exploratory, loosely associated with achieving something, but also concerned with the many engaging interludes along the way. UX is about anticipation, use and reflection. It is a felt experience (McCarthy and Wright, 2004) a unified whole where the experience lies in the relations between the factors rather than in the individual parts. 
With this in mind we investigate the relationships between UX and the locus of sustainable making that is permaculture - a perspective that Bill Mollison, co-founder of the term permaculture defines as:

\begin{abstract}
"... the study of the design of ... sustainable or enduring systems that support human society, both agricultural and intellectual, traditional and scientific, architectural, financial and legal. It is the study of integrated systems, for the purpose of better design and application of such systems." (Mollison, 1988)
\end{abstract}

Both approaches are design practices; UX has come late to sustainable thinking, permaculture has it at its core. Both UX and permaculture are concerned with materials, competences and meanings (Shove, Pantzar and Watson, 2012). Both are concerned with making; a core focus of permaculture concerns gardens and agriculture and UX concerns designing user experiences.

Our approach to bringing permaculture and UX together is to investigate these correspondences through the lens of blending theory, or conceptual integration (Fauconnier and Turner, 2002). Essentially blends take inputs from two conceptual spaces to create a new space which demonstrates new properties that emerge from the blending process. Blending has been used extensively in linguistics, advertising, mathematics and magic to mention just a few of the areas of application. (See Mark Turner's web site at Turner, 2017 for more). Imaz and Benyon (2005) apply blending to $\mathrm{HCl}$ and software engineering and recently Bodker and Klokmose (2016) have looked at blending theory in interaction design with respect to activity theory. Jetter, Reiterer and Geyer (2014) have also used blending in interaction design.

In this paper, we provide a brief background to work on sustainable interaction design before turning to permaculture as a design philosophy and an approach to sustainable design. We briefly introduce the concept of blending, emphasizing Ed Hutchins contribution through the concept of the "material anchor" of blends (Hutchins, 2005). We then describe our approach to building and experiencing blends of permaculture and UX with the aim of contributing to SID through a research through design approach (Storni, 2015) of making gardens.

\section{SUSTAINABLE HCI AS FIELD OF ENQUIRY}

Ideas arising from claims of an Anthropocene, (humankind's visible footprint in geological strata) have seeped into the research of many domains, not least sustainable $\mathrm{HCl}$. Some of the key texts that provide a background to this work are; DiSalvo et al's (2010) mapping of the sustainable $\mathrm{HCl}$ field, Dourish's paper on $\mathrm{HCl}$ and environmental sustainability (Dourish, 2010), Silberman et al's (2014) next steps for sustainable $\mathrm{HCl}$, and Knowles et al's explorations of sustainability and computing (Knowles, Blair, Coulton and Lochrie, 2014).

Importantly, our work addresses questions and observations generated from SIGCHI workshops in recent years, in order to push the research onto new ground, and illuminate ways that sustainable $\mathrm{HCl}$ practice can be realized. For example, we consider how we can make better use of sustainability knowledge from outside $\mathrm{HCl}$, how we can use $\mathrm{HCl}$ research to help achieve sustainability (Silberman, et al., 2014) and what insights $\mathrm{HCl}$ can draw from sustainable communities. Our work also responds to the call for designs of everyday systems that people can use; it takes stock of the diversity of sustainability issues, and grapples with the multiscalar complexity of sustainability (Clear, et al., 2015). We posit that SID must accept a complex systems perspective as a matter of fact.

We also bring ideas of making and doing to the SID discussions. The ten years of workshops and debates have not produced much progress and even the most recent SID publications ask where are we going and what the next steps should be. By embracing a makers' research through design philosophy and working symbiotically with permaculture practitioners - important insights into SID can be realized.

\section{PERMACULTURE AS DESIGN PHILOSOPHY}

Permaculture is a popular manifestation of sustainable practice.

Not only is permaculture a rich area of enquiry into sustainable thinking, living and working, it also provides three analytical elements that inform our work. Firstly, permaculture provides the research with a way of understanding how UX and interaction design might be considered as sustainable practice. Permaculture is a design philosophy and from the outset of this research we considered its potential as an insightful lens for furthering debates within the sustainable $\mathrm{HCl}$ community.

Secondly, as a case study permaculture provides the research with empirical fieldwork through which we might reveal the flows and practices that weave through it. A longitudinal ethnographic study of permaculture in situ and online (Egan 2017) offers a rich description of contemporary sustainable practice that can be considered in tandem with $\mathrm{HCl}$ methods of knowing and doing.

Thirdly, permaculture is a maker's culture that provides new insights into materials, form and design (Ingold, 2012). Practitioners need to work with and be sensitive to the environment in which they are situated and these constraints contribute to the philosophy. 
The community is diffuse and well established in the West, and so-called developing nations, with over 140 organizations worldwide (Perma, 2017). The core design philosophy of permaculture founders' Holmgren and Mollison (Holmgren, 2002; Mollison and Stay, 1994), is enacted with particular emphasis on local conditions, and this contextually rich focus is perhaps a useful stance when considering the development of sustainable digital technologies.

Surprisingly, SID research has largely only hinted at permaculture as a site worthy of enquiry. There is Norton et al's work on the development of an interactive domestic plant guild (Norton, Burke and Tomlinson, 2014), Blevis and Morse's short exploration of alternative agricultures (Blevis and Morse, 2009) and, a keyword mention in Hirsch et al's CHI Panel (Hirsch, et al., 2010).

At its centre the permaculture perspective posits three core ethics that should inform the design of any system: (i) care of the earth, (ii) care of people, and (iii) fair share. The approach to sustainability also utilizes 12 guiding design principles:
(i) Observe and interact
(ii) Catch and store energy
(iii) Obtain a yield
(iv) Apply self-regulation and accept feedback
(v) Use and value renewable resources and services
(vi) Produce no waste
(vii) Design from patterns to details
(viii) Integrate rather than segregate
(ix) Use small and slow solutions
(x) Use and value diversity
(xi) Use edges and value the marginal
(xii) Creatively use and respond to change (Perma, 2017)

Our plan is to utilise these ethics and principles to guide the design of interactive sustainability gardens, employing the Blended Spaces perspective to further understand the nuances of the mixed-media space.

\section{BLENDED SPACES}

As a response to the blurring of physical and digital space, Benyon (2014, p.79) has proposed the concept of a blended space "where a physical space is deliberately integrated in a close-knit way with a digital space". Blended spaces have new properties that emerge from the particular combination of physical and digital, creating a new sense of presence and leading to new ways of interacting, as well as novel user experiences (Benyon, 2012).

The main principle of blending theory is that people come to know things through making projections from two mental spaces in different domains that share a part of their structure with a more generic domain. The projections from the input spaces create new relationships in the blend that did not exist in the original inputs. Classic examples of blending in linguistics include being able to explain the derivation of terms such as 'houseboat' and 'boathouse' from different blends of the input spaces of houses and boats. Other blends include $\mathrm{HCl}$ concepts such as folders, windows and the desk top 'metaphor' (Imaz and Benyon, 2006).

An important part of blending theory is its grounding in an embodied cognition perspective (Fauconnier and Turner, 2002) and hence the need to design for interactions in a way that best suits people. This is designing to establish blends "at a human scale", that is in line with people's perceptual and motor abilities. The importance of embodiment is reinforced by a significant contribution to blending theory by Ed Hutchins arguing for the importance of having a "material anchor" to help people ground their new experiences in something concrete (Hutchins, 2005).

Blended spaces draw on the ideas of blending, applying the concepts to physical and digital spaces. Benyon $(2012 ; 2014)$ develops a view of digital and physical spaces in terms of four characteristics: ontology, topology, volatility, and agency. He argues that for the purpose of creating a good user experiences (UX) these four characteristics constitute the structure of a generic space that both physical and digital spaces share. Ontology concerns the objects in the space, topology concerns the spatial relationships between objects, volatility concerns how quickly objects change and agency concerns what people and artificial agents can do in the space.

For example, in a digital tourism experience of a heritage park the ontology consisted of the points of interest, the topology concerned how those points of interest were related in terms of direction and distance, volatility concerned the changing displays at the various points of interest and the agency concerned the activities that people could engage in at the points of interest.

Digital narratives were developed that enabled visitors to explore the park with episodes triggered by a geo-fence around the points of interest and navigation between points provided by a compass (to show direction) and a display to show distance (O'Keefe and Benyon, 2016). Another example looks at the recent, but familiar idea of bus tracker systems where a digital space provides real-time information about bus times, routes and destinations overplayed on the physical space of the city (Benyon and Resmini, 2016).

\section{INTERACTIVE PERMACULTURE GARDENS AS BLENDED SPACES}


Our current work brings together the space of permaculture with the space of user experience (UX). We do this in the context of a makers culture, described by Tim Ingold (2013) as

'a process of growth. This is to place the maker from the outset as a participant in amongst a world of active materials... in anticipation of what might emerge.' (p.21)

Our materials are plants and their environments of earth and air and the technology that delivers the UX. Through making permaculture gardens and allowing people to experience them we can explore the issues of sustainability in UX. To some extent, then, this process will enable us to understand more clearly the issues in the generic space that underlies the SID agenda. We are looking to uncover, or reverse engineer the issues that designers should attend to, to help the SID agenda to develop. This is illustrated in Figure 1.

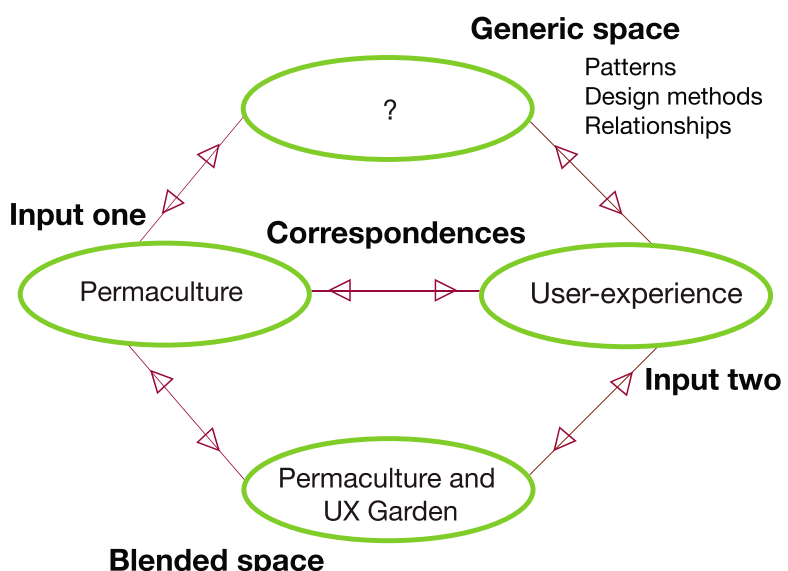

Figure 1: Blending UX and Permaculture

We know that there are some clear correspondences between UX and permaculture. For example, the first permaculture design principle 'observe and interact' maps very well to UX practices such as ethnography and interaction design. The $7^{\text {th }}$ principle 'design from patterns to details' highlights permaculture's and UX's shared interest in design patterns and the works of Christopher Alexander (Alexander, Ishikawa and Silverstein,1977). The $8^{\text {th }}$ principle 'integrate rather than segregate' is similar in perspective to a blended spaces view of design (Imaz and Benyon, 2005). The $11^{\text {th }}$ principle 'use edges and value the marginal' corresponds to notions of liminality and the concept of boundary objects in CSCW (Lee, 2007) which help to bridge different stakeholder groups is also related to this principle.

However, principles such as 'catch and store energy' and 'produce no waste' highlight areas where considerable work still needs to be done in moving toward a $\mathrm{sHCl}$ approach.
The foundation of permaculture is its ethical standpoint. The ethic of 'people care' shares much of the UX focus on human-centred-design (Benyon, 2017), but at present there is little evidence of actual SID practice that aligns with the permaculture ethics of 'earth care' and 'fair share' - a sharing of surpluses. However, it is through designing, making and experiencing interactive permaculture gardens that we are able to develop concepts and ideas that contribute to the sustainable $\mathrm{HCl}$ agenda.

For example, and to keep things simple, let's assume we want to reinforce the message "think global, act local". We could create a small permaculture plant guild and embed some technologies, such as QR codes, near-field communications and Bluetooth beacons - into the garden in an aesthetic way to create a pleasant blended space. The technologies will allow people experiencing the garden to access suitable content - video, audio and animations - that reinforce the message of think global, act local. Perhaps a video of drought in Africa can be related to water preservation in the blended garden, or an audio message from one of the permaculture founders could be played as people interact through a suitable smartphone app. The aim is to design the UX to leverage some permaculture concepts exploiting the material anchor of the plants and planting where possible.

More complex interactions can be envisaged that exploit the ideas of blended spaces in designing physical and digital layers together to create blends that demonstrate emergent properties. Benyon (2012) discusses how the extensions provided by the digital space enable users of the blended space to reach out past the limitations of the physical space and hence to extend people's sense of presence. The abstract principles of permaculture that enable people to reflect on sustainability are made material through the gardens and planting and extended through the interactions provided in the blended space.

\section{CONCLUSION}

The main objective of this work is to gain an understanding of the relationships between UX and permaculture. This will deliver insights as to how digital media development can support the need for people to live and work in more ecologically conscious ways and how UX design can become more sustainable. In this respect, it is an attempt to produce sustainability both in and through design.

We employ a makers approach to understanding permaculture and its relationships with UX in both physical and digital spaces. The work utilizes ideas from blending theory (Fauconnier and Turner, 2002) to generate conceptualizations of ecologically effective SID spaces. We employ material anchors 
to ground complex ideas of sustainability in augmented physical gardens

Thus, the work contributes to a number of on-going aspects of the SID agenda: (i) to originate meaningful conceptual bridges between sustainability and $\mathrm{HCl}$, (ii) to investigate the emergent properties of a permaculture and UX blend by making, (iii) to formulate how digital media can deliver experiences that highlight a sustainability discourse, and (iv) to better understand the physical and digital relationship of permaculture practice.

We are currently developing an exhibit for Scotland's Garden Festival and will continue with the approach of making, planting and experiencing interactive gardens at our university campus. A five-year project is just beginning that will bring permaculture gardens to the campus providing novel and engaging UX for students and staff and promoting a sustainability agenda. Our research journey is documented via the Permaculture Experiences website (Egan, 2017).

\section{REFERENCES}

Alexander, C., Ishikawa, S., \& Silverstein, M. (1977). A Pattern Language: Towns, Buildings, Construction.

Bell, Graham. (1994). The Permaculture Garden. Permanent Publications, Hampshire, UK.

Benyon, D. (2014). Spaces of Interaction, Places for Experience Morgan and Claypool.

Pennsylvania.

Benyon, D. R. (2012) Presence in Blended Spaces Interacting with Computers. 24(4). Pp. 219-226.

Benyon, D. R. (2017) Designing User Experience: a guide to $\mathrm{HCl}$, UX and interaction design. Pearson

Benyon, D. R. and Mival, O. (2015) Blended Spaces for Collaboration. Journal of Computer Supported Collaborative Work. Volume 24, Issue 2 (2015), Page 223-249

Benyon, D. R. and Resmini, A. (2016) Public Transport Commuting as a Cross-channel Experience in Blended Space. Proceedings of Workshop on Experience Design for Multiple Customer Touchpoints. Gothenburg, October

Blevis, E., \& Morse, S. C. (2009). Food, Dude. Interactions, 16(2), 58-62.

Bodker, S. and Klokmose, C. (2016) Dynamics, Multiplicity and Conceptual Blends in $\mathrm{HCl}$ In Proceedings of the SIGCHI conference on Human factors in computing systems $\mathrm{CHI}$ '16

Braungart, M., \& McDonough, W. (2008). Cradle to Cradle - Remaking the Way We Make Things. Vintage Books, London.
Clear, A., Priest, C., Joshi, S,. Nathan, L., Mann, S., Nardi, B. Expanding the Boundaries: A SIGCHIHCI \& Sustainability Workshop, $\mathrm{CHI} 15$ Extended Abstracts,

DiSalvo, C., Sengers, P., Brynjarsdóttir, H. (2010). Mapping the Landscape of Sustainable $\mathrm{HCl}$. Proceedings of the SIGCHI conference on Human factors in computing systems $\mathrm{CHI}$ '10

Dourish, P. (2010). $\mathrm{HCl}$ and Environmental Sustainability: The Politics of Design and the Design of Politics. Proc. of DIS.

Dryzek, D. S. J. S. (2005). Debating the Earth. The Environmental Politics Reader. In Debating the Earth. The Environmental Politics Reader (pp. 302-319).

Egan, C. (2017). Permaculture Experiences website: http://www.callumegan.co.uk retrieved 12/05/2017.

Fauconnier, G. and Turner, M. (2002) The Way We Think. Conceptual Blending and the Mind's Hidden Complexity. Basic Books

Hirsch, T., Sengers, P., Blevis, E., Beckwith, R., \& Parikh, T. (2010). Making food, producing sustainability. Proceedings of the 28th of the International Conference Extended Abstracts on Human Factors in Computing Systems - CHI EA '10,

Holmgren, D. (2002). Permaculture: Principles and Pathways beyond Sustainability. Holmgren Design Services.

Holmgren. D. (2014) How To Change The World With Permaculture Video.

Retrieved October 32015 from https://www.youtube.com/watch?v=TVS45dbNLE.

Hoshi, K. and J. Waterworth, J. (2009) Tangible Presence in Blended Reality Space.

Proceedings of Presence 2009

Hutchins, E. (2005) Material anchors for conceptual blends. Journal of pragmatics. 37(10). Pp. 15551577.

Imaz M. and Benyon, D. (2007) Designing with Blends - Conceptual Foundations of HumanComputer interaction and Software Engineering. The MIT Press.

Ingold, T. (2013) Making: Anthropology, Archaeology, Art and Architecture. Routledge

Ingold, Tim (2013) Making: Anthropology, Archaeology, Art and Architecture. Routledge

Jetter, HC., Reiterer, H. and Geyer, F. (2014). Blended Interaction: understanding natural human-computer interaction in post-WIMP interactive spaces. Personal Ubiquitous Computing. Vol. 18. Issue 5. Pp. 1139-1158. 
Knowles, B., Blair, L., Coulton, P., Lochrie, M. (2014). Rethinking Plan A for Sustainable HCl. Proceedings of the SIGCHI conference on Human factors in computing systems $\mathrm{CHI}$ '14

Knowles, B., Blair, L., Hazas, M., Walker, S. (2013). Exploring Sustainability Research in Computing: Where we are and where we go next? Proc. of UBICOMP.

Latour Bruno (2014) Anthropology at the Time of the Anthropocene - a personal view of what is to be studied. Retrieved October 12015 from http://www. bruno-latour.fr/sites/default/files/139AAA-Washington.pdf.

Lee, C. P. (2007). Boundary negotiating artifacts: Unbinding the routine of boundary objects and embracing chaos in collaborative work. Computer Supported Cooperative Work, 16(3), 307-339.

Hassenzahl, Mark and Tratisnsky, Noam (2006) User experience - a research agenda. Behaviour \& Information Technology, Vol. 25, No. 2.

McCarthy, J. and Wright P. (2004). Technology as experience. The MIT Press.

Mollison, B. (1988) Permaculture: A Designers Manual, Tagari Publications; 2nd edition (Dec. 1988)

Mollison, B., \& Slay, R. (1994). Introduction to Permaculture. Tagari Publications.

Norton, J., Burke, S., \& Tomlinson, B. (2014). Plant Guild Composer: An Interactive Online System to Support Back Yard Food Production. Chi'14.

O'Keefe, B. and Benyon, D. R. (2016) Using the Blended Spaces Framework to design Heritage Stories with Schoolchildren. International Journal of Child-Computer Interaction Volume 6, Pages 7-16

Perma, (2017) Permaculture Association website: https://www.permaculture.org.uk/ retrieved 22.03.2017.

Pink, S., Mackley, K., Mitchell, V., Hanratty, M., Escobar-Tello, C., Bhamra, T., Morosanu, R. (2013). Applying the lens of sensory ethnography to sustainable $\mathrm{HCl}$. ACM Trans. Comput.-Hum. Interact. 20, 4, Article 25.

Shove, E., Pantzar, M., \& Watson, M. (2012). The Dynamics of Social Practice. In The dynamics of social practice. Everyday Life and how it Changes (pp. 1-19).

Silberman, M., Knowles, B., Clear, A., Dillahunt, T. (2014). Next Steps for Sustainable HCl. ACM Interactions. 21, 5 (September 2014), 66-69. DOI=http://dx.doi.org/10.1145/2651820
Storni, C. (2015) A personal perspective on research through design. ACM Interactions 22, 4 (June 2015), 74-76.

DOI=http://dx.doi.org/10.1145/2786974

Tomlinson, B., Blevis, E., Nardi, B., Patterson, D. J., Silberman, M. S., \& Pan, Y. (2013). Collapse informatics and practice. ACM Transactions on Computer-Human Interaction, 20(4), 1-26. http://doi.org/10.1145/2509404.2493431

Turner, M. (2017) http://markturner.org/blending.html\#BOOKS retrieved 22/03/17

Wang, H. H. (2013) A case study on design with conceptual blending. International Journal of Design Creativity. Volume 1. Pp. 109-122

Zalasiewlcz, J., Williams, M., Steffen, W., Crutzen, P. (2010) The New World of the Anthropocene. Environmental Science and Technology, 4 (7). Retrieved October 29 from http://pubs.acs.org/doi/pdf/10.1021/es903118j. 